\title{
Adiposity and Gastrointestinal Malignancy
}

\author{
Joji Kitayama ${ }^{a}$ Masafumi Tabuchib ${ }^{\text {Giichiro Tsurita }}{ }^{\mathrm{a}}$ Makoto Ishikawa ${ }^{\mathrm{a}}$ \\ Kensuke Otania Hirokazu Nagawa ${ }^{a}$ \\ ${ }^{a}$ Department of Surgical Oncology, University of Tokyo, and ${ }^{b}$ Nakameguro Gastrointestinal Clinic, Tokyo, Japan
}

\section{Key Words}

Hyperlipidemia • Gastric cancer · Colorectal cancer •

Adiponectin · Fat volume

\begin{abstract}
Recent epidemiologic studies have shown a positive association between obesity and certain cancers. Our retrospective studies show that hypertriglyceridemia is an independent risk factor for the development of colonic adenoma and nodal metastasis in early gastric and esophageal cancer in men. High-fat condition may be favorable for the growth of malignant cells. Serum level of adiponectin is reduced in patients with advanced gastric cancer, which may be associated with the positive link between adiposity and cancer. In early gastric cancer, patients with undifferentiated type have lower fat volume than those with differentiated type. Adiposity appears to be closely related with various aspects in pathophysiology of gastrointestinal malignancy.
\end{abstract}

Copyright $\odot 2009$ S. Karger AG, Basel

\section{Introduction}

The metabolic syndrome is one of the greatest concerns in developed countries. Abdominal obesity has been shown to be associated with increased risk not only for cardiovascular disease, diabetes and hypertension
[1-7], but also for malignant disease in various organs [8-11]. Since Lew and Garfinkel [12] first reported that being overweight and obesity increased the risk of mortality from cancer, many epidemiologic studies have shown a positive association between obesity and cancers in the endometrium $[11,13]$, breast $[8,14]$ and prostate [15] as well as in the gastrointestinal tract such as the colon $[9,16]$, gallbladder [17], gastric cardia $[18,19]$ and esophagus [20]. These results strongly suggest a mechanical link between adiposity and carcinogenesis. Here, we demonstrate some additional data to support this hypothesis in gastric and colorectal neoplasms.

\section{Hyperlipidemia and Colorectal Neoplasms}

Although previous data suggest a positive association between obesity and the development of colorectal cancer (CRC), it is unknown how adiposity has an impact on the multiple steps in colorectal carcinogenesis. Therefore, we retrospectively performed a large-scale retrospective study to analyze the correlation between the incidence of colorectal adenoma or carcinoma and the fasting serum levels of total cholesterol (TC) and triglycerides (TG) in 4,887 patients who underwent total colonoscopy for the screening of colon cancer [21]. As shown in figure 1, both TG and TC were significantly elevated in patients with adenomas compared with patients without any neoplas-

\section{KARGER}

Fax +4161306 1234

E-Mail karger@karger.ch

www.karger.com (c) $2009 \mathrm{~S}$. Karger AG, Basel

0012-2823/09/0795-0026\$26.00/0

Accessible online at:

www.karger.com/dig
Joji Kitayama

Department of Surgical Oncology, University of Tokyo

Hongo 7-3-1, Bunkyo-ku, Tokyo, 113-8655 (Japan)

Tel. +8133815 5411, ext. 33246, Fax +8133811 6822

E-Mail kitayama-1SU@h.u-tokyo.ac.jp 


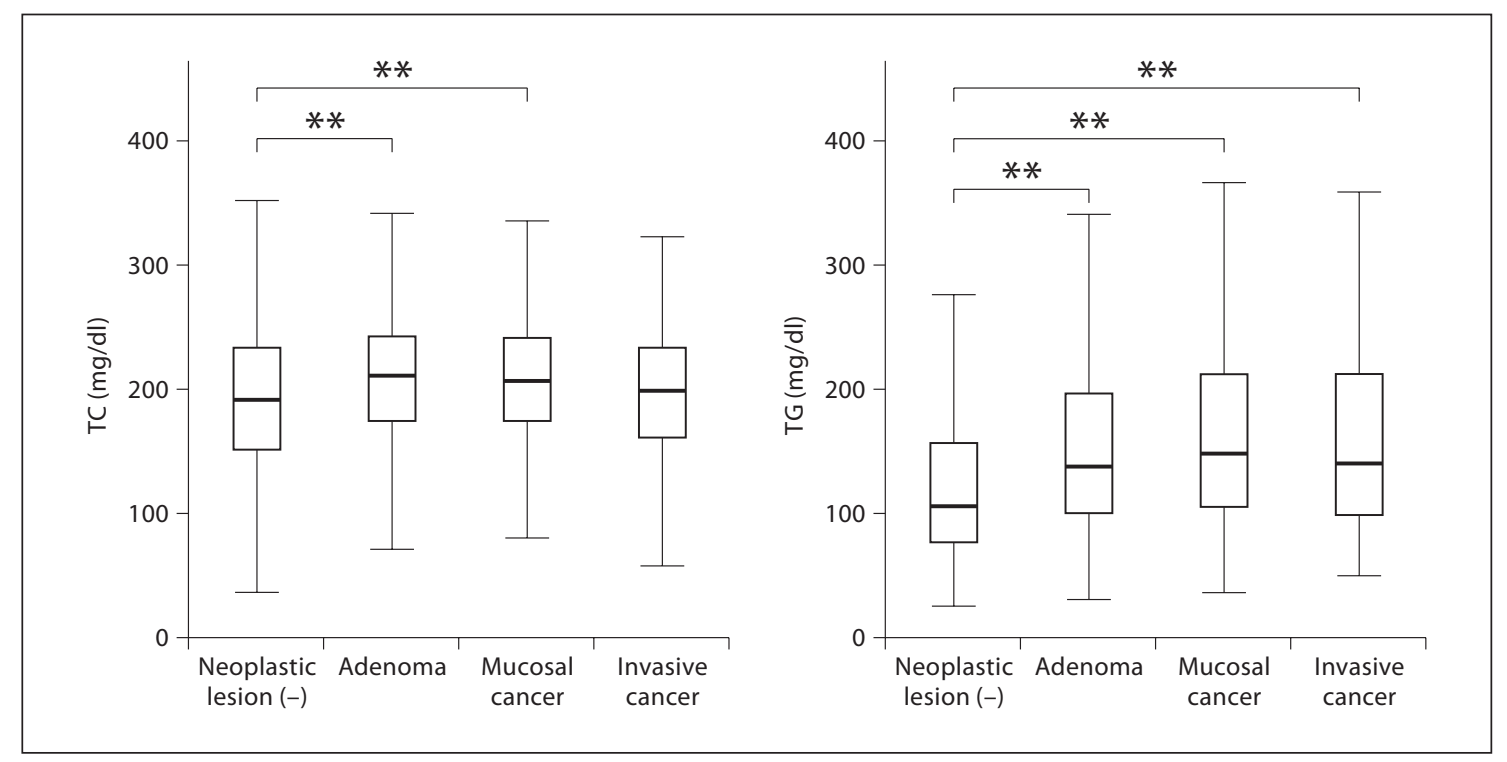

Fig. 1. Means \pm SD of the serum levels of TC and TG of the patients with adenoma $(n=3,821)$, mucosal cancer $(\mathrm{n}=386)$, invasive cancer $(\mathrm{n}=110)$ and without any neoplastic lesions $(\mathrm{n}=956) .{ }^{* *} \mathrm{p}<0.01$.

Table 1. Adjusted OR and 95\% CI for tubular adenoma for a change of 1 SD in male or female patients

\begin{tabular}{|c|c|c|c|c|c|c|}
\hline & \multicolumn{3}{|l|}{ TC } & \multicolumn{3}{|l|}{ TG } \\
\hline Gross OR & 1.3 & $1.21-1.39$ & $<0.0001$ & 1.64 & $1.48-1.82$ & $<0.0001$ \\
\hline Age-adjusted OR & 1.01 & $0.93-1.09$ & 0.79 & 1.34 & $1.21-1.48$ & $<0.0001$ \\
\hline Age-, gender- and TC- or TG-adjusted OR & 1.04 & $0.96-1.13$ & 0.334 & 1.13 & $1.01-1.09$ & 0.013 \\
\hline Age-adjusted OR & 1.09 & $0.98-1.23$ & 0.13 & 1.24 & $1.09-1.43$ & 0.0015 \\
\hline Age- and TC- or TG-adjusted OR & 1.04 & $0.91-1.07$ & 0.555 & 1.23 & $1.07-1.42$ & 0.0041 \\
\hline \multicolumn{7}{|l|}{ Female $(\mathrm{n}=1,890)$} \\
\hline Gross OR & 1.49 & $1.34-1.65$ & $<0.0001$ & 1.42 & $1.25-1.64$ & $<0.0001$ \\
\hline Age-adjusted OR & 1.08 & $0.96-1.21$ & 0.21 & 1.04 & $0.92-1.17$ & 0.56 \\
\hline Age- and TC- or TG-adjusted OR & 1.06 & $0.95-1.02$ & 0.29 & 1.02 & $0.91-1.16$ & 0.7 \\
\hline
\end{tabular}

Hypercholesterolemia and hypertrigliceridemia were defined as TC >220 mg/dl and TG >150 mg/dl, respectively.

tic lesions (TC $207.6 \pm 29.5$ vs. $199.5 \pm 34.3, \mathrm{n}=4,883$, $\mathrm{p}<0.001$; TG $135.0 \pm 82.2$ vs. $108.7 \pm 71.5, \mathrm{n}=4,874$, $\mathrm{p}<0.001)$. The difference is significant in patients with tubular adenoma but not with villous or serrated adenoma (data not shown). Multiple logistic regression analysis considering age and gender revealed that TG was determined as an independent correlation factor in male but not in female patients (table 1). The levels of TG in patients with invasive carcinoma did not show significant elevation compared to patients with adenoma. Those facts suggest that hypertriglyceridemia is an independent risk factor for the development of colonic adenoma in men, but not in females. 
Table 2. Fasting serum levels of TC, TG and FBS in patients with colorectal adenoma, mucosal cancer and invasive cancer

\begin{tabular}{lllll}
\hline & No adenoma $(\mathrm{n}=92)$ & Adenoma $(\mathrm{n}=682)$ & Mucosal cancer $(\mathrm{n}=70)$ & Invasive cancer $(\mathrm{n}=23)$ \\
\hline TC & $203.90 \pm 32.92$ & $209.03 \pm 27.19$ & $208.07 \pm 21.48$ & $203.57 \pm 25.52$ \\
TG & $111.59 \pm 57.24$ & $134.53 \pm 68.31^{*}$ & $147.14 \pm 81.14^{*}$ & $126.60 \pm 47.11$ \\
FBS & $100.80 \pm 29.49$ & $105.79 \pm 26.05$ & $107.55 \pm 26.75$ & $121.86 \pm 43.75^{+}$ \\
\hline
\end{tabular}

${ }^{*} \mathrm{p}<0.01$ against no adenoma; ${ }^{+} \mathrm{p}<0.001$ against no adenoma, $\mathrm{p}<0.01$ against adenoma, $\mathrm{p}<0.05$ against mucosal cancer.

Table 3. OR of each variable for the development of adenoma, carcinoma and invasive carcinoma

\begin{tabular}{lcc}
\hline Variable & p value & \multicolumn{1}{l}{ OR } \\
\hline Risk for adenoma in total patients $(\mathrm{n}=867)$ \\
Age & $<0.001$ & $2.18(1.74-2.77)$ \\
Gender & $<0.001$ & $3.20(1.92-5.42)$ \\
BMI & 0.011 & $1.38(1.08-1.78)$ \\
TG & 0.443 & $1.12(0.85-1.52)$ \\
FBS & 0.295 & $0.87(0.69-1.16)$ \\
Risk for carcinoma in patients with adenoma $(\mathrm{n}=775)$ \\
Age & $<0.001$ & $1.51(1.20-1.93)$ \\
Gender & $<0.001$ & $3.33(1.81-6.62)$ \\
BMI & 0.236 & $1.16(0.91-1.47)$ \\
TG & 0.859 & $1.02(0.81-1.26)$ \\
FBS & 0.617 & $1.05(0.85-1.27)$ \\
Risks for invasive carcinoma in patients & with carcinoma $(\mathrm{n}=93)$ \\
Age & 0.082 & $1.61(0.96-2.85)$ \\
Gender & 0.554 & $0.62(0.13-3.44)$ \\
BMI & 0.096 & $1.61(0.93-2.93)$ \\
TG & 0.121 & $0.55(0.24-1.07)$ \\
FBS & 0.027 & $1.74(1.07-2.93)$ \\
\hline
\end{tabular}

Figures in parentheses are $95 \% \mathrm{CI}$. OR means ratio of male against female in gender, and ratios for a change of $1 \mathrm{SD}$ in other variables.

\section{Hyperglycemia and Colorectal Neoplasms}

Among the patients, we could also evaluate serum levels of fasting blood sugar (FBS) in 867 patients [22]. The serum levels of FBS as well as TC and TG are expressed in table 2. TG and FBS, but not TC, showed positive association with the presence of colonic neoplasia. Patients with adenoma or carcinoma in situ showed significantly elevated TG level compared to those without adenoma $(\mathrm{p}<0.01)$, while patients with invasive cancer showed a similar level of TG as those without adenoma. In contrast, FBS level was only slightly increased in patients with adenoma or carcinoma in situ $(\mathrm{p}>0.05)$, whereas it was markedly elevated in patients with invasive cancer compared to those without invasive cancer. As shown in table 3, multivariate logistic regression analysis revealed that age, gender and body mass index (BMI) were independent risk factors for adenoma in total patients. In patients with adenoma, age and gender, but not BMI, were independently associated with the increased risk for in situ carcinoma development. In those steps, neither TG nor FBS were identified as independent risk factors. However, in 93 patients with carcinoma lesions, only FBS showed significant association with the risk of invasive cancer with an OR of $1.74(\mathrm{p}<0.05)$. TG showed a rather negative trend for invasive cancer with an OR of 0.55 . These data suggest that hyperglycemia may correlate with the late step of the development of CRC.

\section{Hyperlipidemia and Lymph Node Metastasis in Early Gastric Cancer}

In contrast to CRC, serum TC and TG do not show significant differences between patients with early gastric cancer (EGC) and normal controls. Interestingly, however, we could detect the correlation between serum lipid levels and lymphatic metastasis in patients with EGC [23]. In 353 patients with EGC, 33 with positive lymph node metastasis showed significantly higher levels of TC and TG than the 320 patients without lymph node metastasis (fig. 2). The same tendency was observed in patients with early esophageal cancer, but not in patients with CRC (fig. 2).

Multivariate analysis demonstrates that hypertriglyceridemia, but not hypercholesterolemia, as well as submucosal invasion and lymphatic involvement were found to be independent risk factors for lymph node metastasis in 255 male patients (table 4). On the other hand, tumor size and undifferentiated type were independent factors, while depth and lymphatic invasion lost significance in 
Fig. 2. Means \pm SD of preoperative serum levels of TC and TG of EGC, CRC and esophageal cancer. In any patients, serum lipid levels were examined at early morning before breakfast on 2-6 days before operation after admission. ${ }^{*} \mathrm{p}<0.05$.

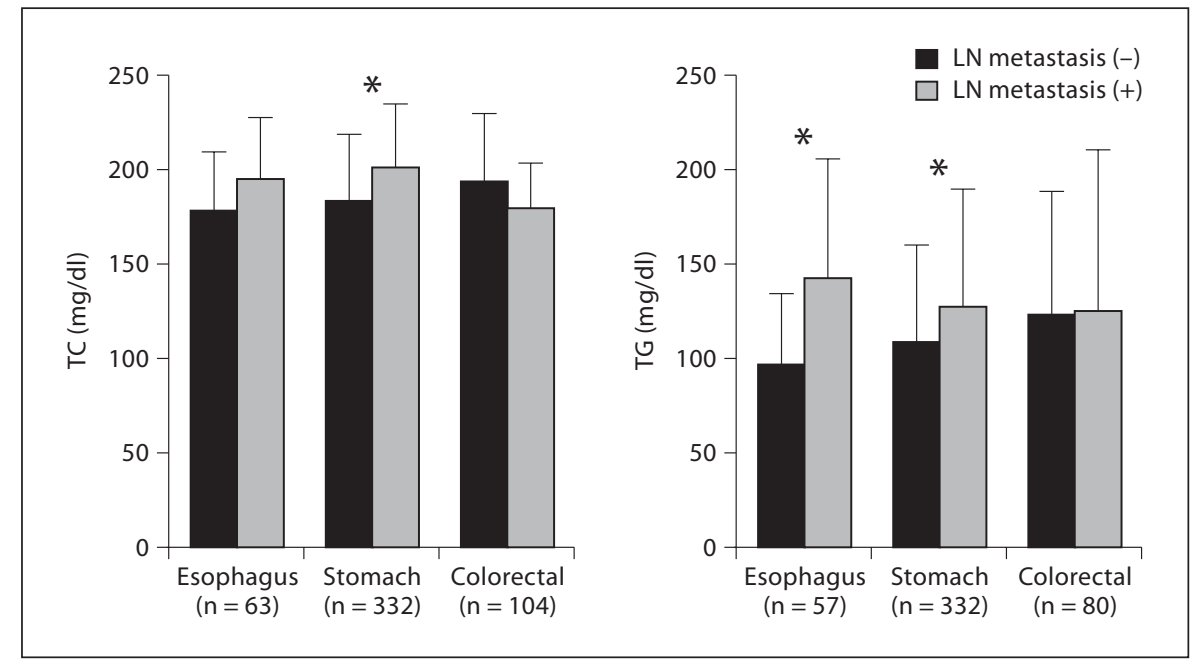

female patients (table 4). These data show that elevated serum TG levels might bring favorable circumstances for the development of lymph node metastasis in the early stage of gastric cancer (GC), at least in male patients.

\section{Serum Adiponectin Levels and GC}

The adipose tissue produces various growth factors or hormones called adipokines [24]. Adiponectin is one of the active adipokines which is related to the pathogenesis of diabetes through the modulation of glucose and fatty acid metabolism and insulin sensitivity in various stromal or epithelial cells $[25,26]$. Interestingly, circulating levels of adiponectin have been reported to be inversely related with BMI and to be reduced in conditions of insulin resistance $[25,27]$. Furthermore, we examined the serum adiponectin levels in patients with GC [28]. The plasma adiponectin levels were significantly decreased in patients with GC compared to healthy controls (fig. 3). Moreover, the adiponectin concentration tended to be reduced as the tumor stage increased (stage 1: $9.9 \pm 6.9$ $\mu \mathrm{g} / \mathrm{ml}$; stage 2: $8.7 \pm 5.5 \mu \mathrm{g} / \mathrm{ml}$; stage 3: $8.6 \pm 4.1 \mu \mathrm{g} / \mathrm{ml}$; stage $4: 5.2 \pm 6.2 \mu \mathrm{g} / \mathrm{ml}$ ), although BMI did not show any difference between the stages. Similar results have been reported in other malignancies, such as endometrial [29], breast $[29,30]$ and prostate $[31,32]$ cancers. This fact suggests that low plasma adiponectin levels are correlated with an increased risk for cancer, and raises the possibility that adiponectin has a potential role in cancer progression. In fact, many recent reports have suggested the antitumor effects of adiponectin both in vitro and in vivo
Table 4. Multivariate analysis of risk factors for lymph node metastasis in male and female EGC

\begin{tabular}{lrll}
\hline & OR & $95 \%$ CI & p value \\
\hline Male & & & \\
$\quad$ Lymphatic invasion & 4.21 & $1.68-10.56$ & 0.0022 \\
$\quad$ Submucosal involvement & 21.09 & $2.32-191.33$ & 0.0067 \\
$\quad$ Size & 1.26 & $0.39-4.03$ & 0.6993 \\
$\quad$ Hypercholesterolemia & 3.59 & $0.84-15.21$ & 0.0831 \\
$\quad$ Hypertriglyceridemia & 3.57 & $1.11-11.45$ & 0.0327 \\
Female & & & \\
$\quad$ Lymphatic invasion & 3.42 & $0.54-21.59$ & 0.1919 \\
$\quad$ Submucosal involvement & 2.58 & $0.51-13.12$ & 0.2523 \\
$\quad$ Size & 15.71 & $1.80-136.71$ & 0.0126 \\
$\quad$ Undifferentiated type & 10.03 & $1.03-97.28$ & 0.0467 \\
& & &
\end{tabular}

Factors identified in univariate analysis were included in multivariate analysis.

[33-36]. Since the circulating adiponectin levels are reduced in obesity, this adipokine may have an important protective role against carcinogenesis.

\section{Fat Volume in Patients with EGC and CRC}

Obesity is increased volume of the adipose tissue, and thus we next examined the fat volumes in patients with EGC and CRC. For subjective quantification, we examined the volume of visceral and subcutaneous fat in 1 slice of CT scan using the Fat Scan software (N2 System K.K., 


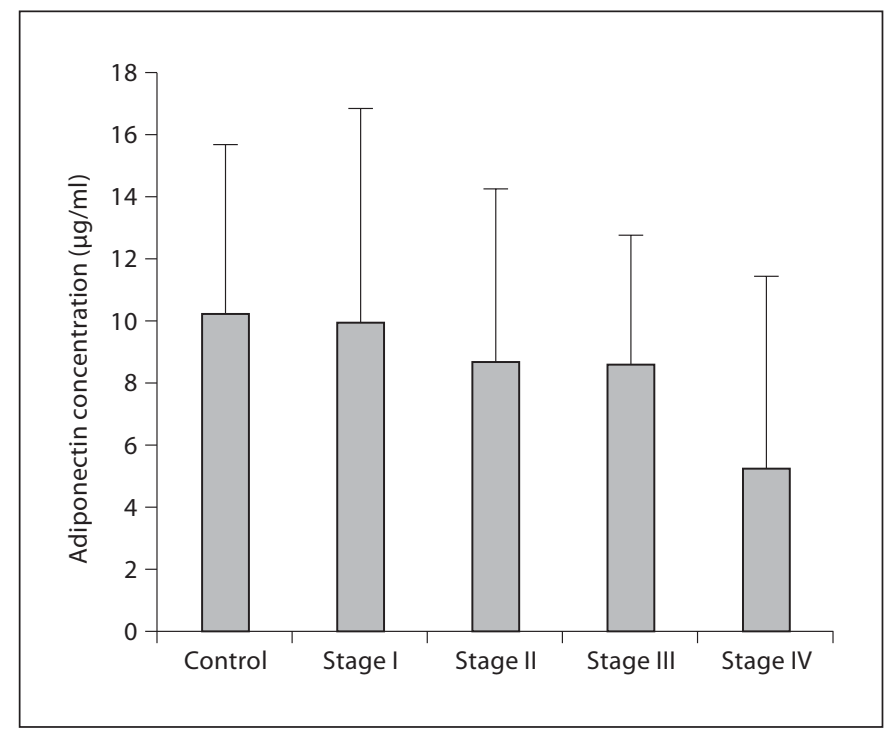

Fig. 3. Fasting plasma levels of adiponectin were determined in 75 GC patients and 52 healthy controls using the enzyme-linked immunosorbent assay. $\mathrm{p}=0.26$.

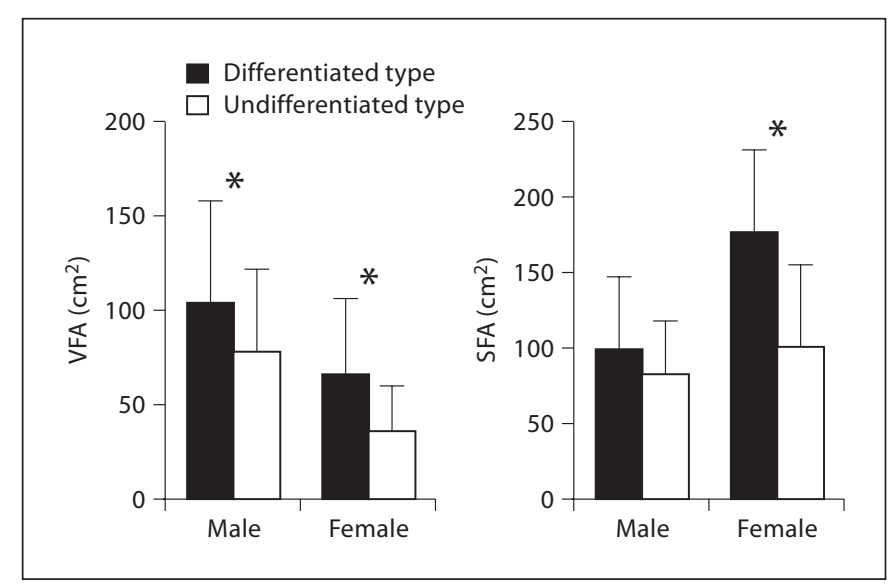

Fig. 4. VFA and SFA measured with the Fat Scan software in male (differentiated-type cancer: $\mathrm{n}=151$; undifferentiated-type cancer: $\mathrm{n}=23$ ) and female (differentiated-type cancer: $\mathrm{n}=24$; undifferentiated-type cancer: $\mathrm{n}=12$ ) patients with EGC. ${ }^{*} \mathrm{p}<0.05$.

Osaka, Japan) in $210 \mathrm{GC}$ and 147 CRC patients [37]. As shown in table $5, \mathrm{BMI}$ and total fat area (TFA) showed no significant difference between patients with GC and CRC cancer. Both BMI and TFA were the same in male and female patients. In contrast, visceral fat area (VFA) was significantly larger in male patients, while subcutaneous fat area (SFA) was larger in female patients, which is con-
Table 5. BMI and fat areas of patients with EGC and GC

\begin{tabular}{|c|c|c|c|}
\hline Male $(\mathrm{n}=276)$ & $\mathrm{GC}(\mathrm{n}=174)$ & $\operatorname{CRC}(\mathrm{n}=102)$ & $\mathrm{p}$ value \\
\hline BMI & $22.8 \pm 2.9$ & $22.9 \pm 3.1$ & 0.979 \\
\hline $\mathrm{TFA}, \mathrm{cm}^{2}$ & $199.6 \pm 89.2$ & $185.2 \pm 85.4$ & 0.175 \\
\hline VFA, $\mathrm{cm}^{2}$ & $101.2 \pm 52.7$ & $91.9 \pm 51.9$ & 0.144 \\
\hline $\mathrm{SFA}, \mathrm{cm}^{2}$ & $98.4 \pm 45.0$ & $93.2 \pm 43.9$ & 0.24 \\
\hline VFA/SFA & $1.07 \pm 0.41$ & $1.05 \pm 0.53$ & 0.434 \\
\hline Female $(\mathrm{n}=81)$ & $\mathrm{GC}(\mathrm{n}=36)$ & CRC $(n=45)$ & $\mathrm{p}$ value \\
\hline BMI & $21.9 \pm 3.3$ & $21.4 \pm 3.2$ & 0.372 \\
\hline $\mathrm{TFA}, \mathrm{cm}^{2}$ & $208.7 \pm 93.2$ & $175.6 \pm 82.6$ & 0.081 \\
\hline VFA, $\mathrm{cm}^{2}$ & $56.6 \pm 36.8$ & $50.2 \pm 29.5$ & 0.608 \\
\hline $\mathrm{SFA}, \mathrm{cm}^{2}$ & $152.1 \pm 64.6$ & $125.4 \pm 60.2$ & $0.037^{*}$ \\
\hline VFA/SFA & $0.43 \pm 0.34$ & $0.47 \pm 0.42$ & 0.464 \\
\hline
\end{tabular}

Data are averages \pm SD. ${ }^{*} \mathrm{p}<0.05$. sistent with data of the general population without cancer [38]. However, when VFA and SFA were separately compared in each sex, both parameters showed mostly the same values. Interestingly, both parameters tended to be high in patients with GC compared with those with CRC, although the differences were not statistically significant, except for SFA in female patients.

Another interesting finding in this study is that the fat volumes in patients with GC were significantly different by their histological types. As shown in figure 4, in male patients, VFA was significantly smaller in undifferentiated than differentiated type. SFA also tended to be smaller in undifferentiated type $(\mathrm{p}=0.07)$. The trend was more prominent in female patients. VFA $(\mathrm{p}=0.004)$ and SFA $(p<0.001)$ were markedly smaller in patients with undifferentiated GC than in those with differentiated histology. Compared with the general Japanese population, fat areas are considered to be reduced in patients with undifferentiated GC. These facts suggest that reduced fat volume may be mechanically related with the development of undifferentiated but not differentiated GC. Furthermore, TFA, VFA and SFA did not show a significant difference between mucosal and submucosal cancer in patients with differentiated cancer, whereas those values tended to be lower in submucosal than in mucosal cancer in patients with undifferentiated GC. With these results, we can raise a possibility that reduced fat volume may be favorable for submucosal invasion of undifferentiated 
GC. Another speculation is that undifferentiated but not differentiated GC may already have systemic effects, inducing a reduction of subcutaneous fat volumes in early stage.

\section{Conclusion}

Increased body weight is certainly associated with increased death rates for cancers at multiple specific sites including the gastrointestinal tract [39]. Our data on the patients with gastric and CRC are mostly consistent with these results. Hyperlipidemia may provide a favorable circumstance for the growth of malignant cells. Adiponectin may be the key molecule to explain the positive link between adiposity and cancer. Restriction of energy intake may be another reasonable strategy to prevent GC and CRC in obese people.

\section{Disclosure Statement}

The authors declare that no financial or other conflict of interest exists in relation to the content of the article.

\section{References}

1 Armstrong B, Doll R: Environmental factors and cancer incidence and mortality in different countries, with special reference to dietary practices. Int J Cancer 1975; 15:617631.

$\checkmark 2$ Azevedo A, Ramos E, von Hafe P, Barros H: Upper-body adiposity and risk of myocardial infarction. J Cardiovasc Risk 1999;6: 321-325.

3 Donahue RP, Abbott RD, Bloom E, Reed DM, Yano K: Central obesity and coronary heart disease in men. Lancet 1987;i:821824.

4 Ducimetiere P, Richard J, Cambien F: The pattern of subcutaneous fat distribution in middle-aged men and the risk of coronary heart disease: the Paris Prospective Study. Int J Obes 1986;10:229-240.

5 Lapidus L, Bengtsson C, Lissner L: Distribution of adipose tissue in relation to cardiovascular and total mortality as observed during 20 years in a prospective population study of women in Gothenburg, Sweden. Diabetes Res Clin Pract 1990;10(suppl 1):S185S189.

-6 Larsson B, Svardsudd K, Welin L, Wilhelmsen L, Bjorntorp P, Tibblin G: Abdominal adipose tissue distribution, obesity, and risk of cardiovascular disease and death: 13 year follow up of participants in the study of men born in 1913. Br Med J (Clin Res Ed) 1984; 288:1401-1404

7 Reeder BA, Senthilselvan A, Despres JP, Angel A, Liu L, Wang $\mathrm{H}$, et al: The association of cardiovascular disease risk factors with abdominal obesity in Canada. Canadian Heart Health Surveys Research Group. Cmaj 1997;157(suppl 1):S39-S45.

Adiposity and Gastrointestinal Malignancy
-8 Folsom AR, Kaye SA, Prineas RJ, Potter JD, Gapstur SM, Wallace RB: Increased incidence of carcinoma of the breast associated with abdominal adiposity in postmenopausal women. Am J Epidemiol 1990;131:794803.

9 Giovannucci E: Insulin and colon cancer. Cancer Causes Control 1995;6:164-179.

10 Hartz AJ, Rupley DC, Rimm AA: The association of girth measurements with disease in 32,856 women. Am J Epidemiol 1984;119: 71-80.

11 Schapira DV, Kumar NB, Lyman GH, Cavanagh D, Roberts WS, LaPolla J: Upper-body fat distribution and endometrial cancer risk. JAMA 1991;266:1808-1811.

12 Lew EA, Garfinkel L: Variations in mortality by weight among 750,000 men and women. J Chronic Dis 1979;32:563-576.

13 Hill HA, Austin H: Nutrition and endometrial cancer. Cancer Causes Control 1996;7: 19-32.

14 Hunter DJ, Willett WC: Nutrition and breast cancer. Cancer Causes Control 1996;7:5668.

5 Kolonel LN: Nutrition and prostate cancer. Cancer Causes Control 1996;7:83-44.

19 Chow WH, Blot WJ, Vaughan TL, Risch HA, Gammon MD, Stanford JL, et al: Body mass index and risk of adenocarcinomas of the esophagus and gastric cardia. J Natl Cancer Inst 1998;90:150-155.

20 Lagergren J, Bergstrom R, Nyren O: Association between body mass and adenocarcinoma of the esophagus and gastric cardia. Ann Intern Med 1999;130:883-890.

21 Tabuchi M, Kitayama J, Nagawa H: Hypertriglyceridemia is positively correlated with the development of colorectal tubular adenoma in Japanese men. World J Gastroenterol 2006;12:1261-1264.

22 Tabuchi M, Kitayama J, Nagawa H: Hyperglycemia and hypertriglyceridemia may associate with the adenoma-carcinoma transition in colorectal epithelial cells. J Gastroenterol Hepatol 2008;23:985-987.

23 Kitayama J, Hatano K, Kaisaki S, Suzuki H, Fujii S, Nagawa H: Hyperlipidaemia is positively correlated with lymph node metastasis in men with early gastric cancer. Br J Surg 2004;91:191-198.

24 Guerre-Millo M: Adipose tissue and adipokines: for better or worse. Diabetes Metab 2004;30:13-19.

16 Potter JD: Nutrition and colorectal cancer. Cancer Causes Control 1996;7:127-146.

17 Zatonski WA, Lowenfels AB, Boyle P, Maisonneuve P, Bueno de Mesquita HB, Ghadirian $\mathrm{P}$, et al: Epidemiologic aspects of gallbladder cancer: a case-control study of the SEARCH Program of the International Agency for Research on Cancer. J Natl Cancer Inst 1997;89:1132-1138.

18 Hansson LE, Nyren O, Bergstrom R, Wolk A, Lindgren A, Baron J, et al: Nutrients and gastric cancer risk: a population-based casecontrol study in Sweden. Int J Cancer 1994; $57: 638-644$.
25 Arita Y, Kihara S, Ouchi N, Takahashi M, Maeda K, Miyagawa J, et al: Paradoxical decrease of an adipose-specific protein, adiponectin, in obesity. Biochem Biophys Res Commun 1999;257:79-83.

26 Diez JJ, Iglesias P: The role of the novel adipocyte-derived hormone adiponectin in human disease. Eur J Endocrinol 2003;148: 293-300. 
-27 Hotta K, Funahashi T, Arita Y, Takahashi M, Matsuda M, Okamoto Y, et al: Plasma concentrations of a novel, adipose-specific protein, adiponectin, in type 2 diabetic patients. Arterioscler Thromb Vasc Biol 2000;20: 1595-1599.

-28 Ishikawa M, Kitayama J, Kazama S, Hiramatsu T, Hatano K, Nagawa H: Plasma adiponectin and gastric cancer. Clin Cancer Res 2005;11:466-472.

29 Dal Maso L, Augustin LS, Karalis A, Talamini R, Franceschi S, Trichopoulos D, et al: Circulating adiponectin and endometrial cancer risk. J Clin Endocrinol Metab 2004; 89:1160-1163.

-30 Miyoshi Y, Funahashi T, Kihara S, Taguchi T, Tamaki Y, Matsuzawa Y, et al: Association of serum adiponectin levels with breast cancer risk. Clin Cancer Res 2003;9:5699-5704.

- 31 Goktas S, Yilmaz MI, Caglar K, Sonmez A, Kilic S, Bedir S: Prostate cancer and adiponectin. Urology 2005;65:1168-1172.
2 Michalakis K, Williams CJ, Mitsiades N, Blakeman J, Balafouta-Tselenis S, Giannopoulos A, et al: Serum adiponectin concentrations and tissue expression of adiponectin receptors are reduced in patients with prostate cancer: a case control study. Cancer Epidemiol Biomarkers Prev 2007;16:308-313.

33 Kang JH, Lee YY, Yu BY, Yang BS, Cho KH, Yoon DK, et al: Adiponectin induces growth arrest and apoptosis of MDA-MB-231 breast cancer cell. Arch Pharm Res 2005;28:12631269.

34 Bub JD, Miyazaki T, Iwamoto Y: Adiponectin as a growth inhibitor in prostate cancer cells. Biochem Biophys Res Commun 2006; 340:1158-1166.

35 Dieudonne MN, Bussiere M, Dos Santos E, Leneveu MC, Giudicelli Y, Pecquery R: Adiponectin mediates antiproliferative and apoptotic responses in human MCF7 breast cancer cells. Biochem Biophys Res Commun 2006;345:271-279.
6 Ishikawa M, Kitayama J, Yamauchi T, Kadowaki T, Maki T, Miyato H, et al: Adiponectin inhibits the growth and peritoneal metastasis of gastric cancer through its specific membrane receptors AdipoR1 and AdipoR2. Cancer Sci 2007;98:1120-1127.

37 Otani K, Kitayama J, Kaisaki S, Ishigami H, Hidemura A, Fujishiro M, et al: Early gastric cancer shows different associations with adipose tissue volume depending on histological type. Gastric Cancer 2008;11:86-95.

38 Eguchi M, Tsuchihashi K, Saitoh S, Odawara Y, Hirano T, Nakata T, et al: Visceral obesity in Japanese patients with metabolic syndrome: reappraisal of diagnostic criteria by CT scan. Hypertens Res 2007;30:315-323.

39 Calle EE, Rodriguez C, Walker-Thurmond $\mathrm{K}$, Thun MJ: Overweight, obesity, and mortality from cancer in a prospectively studied cohort of U.S. adults. N Engl J Med 2003;348: 1625-1638. 